\title{
Fonksiyonel Konstipasyonu Olan Yetişkin Bireylerin Posa, Sıvı ve Vitamin Mineral Alımlarının Değerlendirilmesi
}

\author{
Evaluation of Fiber, Fluid and Vitamin Mineral Intakes of Adult Individuals with Functional \\ Constipation
}

\author{
Burcu Ateş Özcan ${ }^{1}$, Mendane Saka²
}

Geliş tarihi/Received: 02.08.2018 • Kabul tarihi/Accepted: 20.11.2018

\section{ÖZET}

Amaç: Fonksiyonel konstipasyonu olan yetişkin bireylerin diyet ile günlük posa, sıvı, vitamin ve mineral alımlarının değerlendirilmesidir.

Bireyler ve Yöntem: Çalışma Bayındır Hastanesi Gastroenteroloji polikliniğine başvuran, doktor tarafından fonksiyonel konstipasyon tanısı konmuş 19-64 yaş arasındaki 59'u kadın 26’sı erkek olmak üzere toplam 85 birey ile yapılmıştır. Yüzyüze görüşme yöntemi ile hastaların demografik özellikleri (yaş, eğitim düzeyi, meslek vb.) anket formuna kaydedilmiş, antropometrik ölçümleri (boy uzunluğu, vücut ağırlığı, bel ve kalça çevresi ölçümleri) yapılmış, hastalardan üç günlük besin tüketim kaydı alınmıştır.

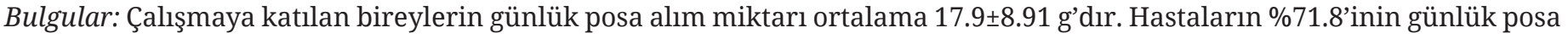

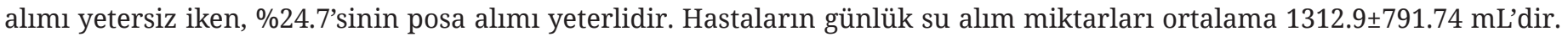
Kadın hastaların günlük su alım ortalamaları $(1413.6 \pm 842.5 \mathrm{~mL}$ ) erkek hastaların ortalamalarından (1084.6 $\pm 617.5 \mathrm{~mL})$ fazladır (p<0.05). Hastaların vitamin ve mineral alımları Diyetle Referans Alım Düzeyi (DRI) önerilerine göre değerlendirildiğinde, özellikle folat, tiamin, niasin, $\mathrm{B}_{6}$ ve $\mathrm{C}$ vitaminleri ile potasyum, magnezyum, demir ve kalsiyum minerallerini yetersiz düzeyde aldıkları saptanmıştır.

Sonuç: Konstipasyonu olan bireylerin günlük diyet ile diyet posası, su, vitamin ve mineral alımları düşüktür. Konstipasyonun önlenmesinde yeterli ve dengeli beslenme ile birlikte yaşam tarzı değişikliği ön plana çıkmaktadır.

Anahtar kelimeler: Fonksiyonel konstipasyon, posa, sıvı alımı, beslenme, vitamin ve mineraller

\section{ABSTRACT}

Aim: This study aimed to evaluate the daily dietary intakes of fiber, fluid, vitamins and minerals in adults with functional constipation.

Subjects and Method: The study was conducted on a total of 85 subjects (59 females, 26 males), aged between 19-64 years who were referred to Bayındır Hospital Gastroenterology outpatient clinic with a diagnosis of functional constipation. The demographic characteristics of the patients (age, education level, profession, etc.) were recorded in the questionnaire form by face-to-face interview method, anthropometric measurements of the patients (height, body weight, waist and hip circumference measurements) and three days of food consumption records were taken from the patients.

1. İletişim/Correspondence: Okan Üniversitesi, Sağllk Bilimleri Fakültesi, Beslenme ve Diyetetik Bölümü, İstanbul, Türkiye • E-posta: burcu.ozcan@okan.edu.tr (ㄱ) https://orcid.org/0000-0003-2627-0167
2. Başkent Üniversitesi, Sağlık Bilimleri Fakültesi, Beslenme ve Diyetetik Bölümü, Ankara, Türkiye

๑ https://orcid.org/0000-0002-5516-426X 
Results: The mean daily fiber intake of the patients was $17.9 \pm 8.91 \mathrm{~g}$. The adequacy of fiber intake was found to be inadequate in $71.8 \%$ of patients, while $24.7 \%$ of patients consumed adequate amounts of fiber. The mean daily water intake of the patients was $1312.9 \pm 791.74 \mathrm{~mL}$. The average daily water intake of female patients $(1413.6 \pm 842.5 \mathrm{~mL})$ was also higher than the average consumption of male patients $(1084.6 \pm 617.5 \mathrm{~mL})(\mathrm{p}=0.035)$. Mean daily intakes of vitamins and minerals, particularly folic acid, thiamine, niacin, vitamin $\mathrm{B}_{6}$ and vitamin $\mathrm{C}$, potassium, magnesium, iron and calcium, were lower than daily recommended intakes (DRI).

Conclusion: Daily intake of dietary fiber, vitamins and minerals and water intake of patients who suffered from constipation were found to be inadequate. Moreover, physical activity levels of these patients are also found to be low. In order to prevent constipation, changing lifestyle in addition to an adequate and balanced nutrition is necessary.

Keywords: Functional constipation, fiber, fluid intake, nutrition, vitamin and minerals

\section{GíRiş}

Fonksiyonel konstipasyon, defekasyon siklığının azalması, dışkı kıvamında sertleşme, ıkınma, tamamlanmamış boşaltım hissi ile tanımlanan bir semptomdur. Fiziksel, mental ve sosyal iyilik halini etkileyerek yaşam kalitesini düşürür $(1,2)$. Sıklığı kullanılan tanımlara göre farklılık göstermekle birlikte genel popülasyonun yaklaşık \%20'sinde görülmektedir (3).

Konstipasyonun tedavisinde öncelikli olarak yaşam tarzı değişikliğini içeren farmakolojik olmayan tedavi yöntemleri önerilmektedir. Bu yöntem ile başarı sağlanamadığı durumlarda farmakolojik ajanlar, biyofeedback ve konstipasyonun şiddetine göre cerrahi tedavi yöntemleri uygulanabilir. Yaşam tarzı değişikliği, posa ve sıvı alımlarının arttırılması ve düzenli yapılan fiziksel aktiviteyi içermektedir (4).

Yeterli ve dengeli beslenmede, cinsiyete ve yaş gruplarına göre besin ögesi gereksinimleri ve alınması gereken öneriler baz alınır. Konstipasyonu önlemek için diyetin yeterli enerji ve posa dahil tüm besin ögelerini içermesi gerekir (5). Diyet posası, sindirim enzimlerine dirençli besin bileşenlerinden oluşmaktadır ve başlıca tahıl, meyve ve sebzelerde bulunmaktadır. İnsan ince bağırsağında sindirilemeyen ancak kalın bağırsakta tamamen ya da kısmen fermente olabilen diyet posası, suda çözünebilen ve suda çözünmeyen olmak üzere iki gruba ayrılmaktadır (6).
Çözünür posa, bağırsak lümenindeki basıncı azaltır, bağırsak çapını genişletir, bağırsak hareketini arttırır (7). Çözünür posa su çekerek jel kıvam oluşturur. Böylece dışkının hacmini ve yumuşaklığını arttırarak lümenden daha rahat geçmesini sağlar (8). Aynı zamanda gastrik boşalımı yavaşlatır. Çözünmez posada karbonhidrat zinciri suda çözünmez ve fermantasyon sinırlıdır (9). Suyu bünyesinde tutarak bağırsaklardaki atıkların yumuşamasına ve genişlemesine yardımcı olup artık maddelerin sindirim sistemine daha çabuk ve daha kolay geçmesini sağlar. Böylece çözünmez posa, konstipasyon ve onunla birlikte oluşan rahatsızlıkları önler (7).

Diyet posası alım miktarları değişik yaş ve özel durumlara göre farklılık göstermekle birlikte sağlıklı bireyler için önerilen alım miktarları alınan her 1000 kkal için $14 \mathrm{~g}$ ya da günlük kadınlar için $25 \mathrm{~g}$, erkekler için 38 g’dır (10). Bütün önerilen miktarlar için yeterli sıvı alımı önemlidir. Fonksiyonel konstipasyonu olan hastaların komplikasyonlarının giderilmesi için ise en az 20 g/gün posa olmak üzere günlük 20-35 g arası posa alımı önerilirken, hastalarda düşük olduğu gözlenen posa alımının bu miktarlara yavaş yavaş çıkarılması tavsiye edilmektedir (5). Bu çalışmada, fonksiyonel konstipasyonu olan yetişkin bireylerin diyet ile günlük posa, sıvı, vitamin ve mineral alımlarının değerlendirilmesi amaçlanmıştır. 


\section{BIREYLER VE YÖNTEM}

\section{Araştırma Yeri, Zamanı ve Örneklem Seçimi}

$\mathrm{Bu}$ araştırma, Başkent Üniversitesi Tıp ve Sağlık Bilimleri Araştırma Kurulu Etik Kurul Kararı alındıktan sonraki 3 ay içerisinde Bayındır Hastanesi Gastroenteroloji polikliniğine başvuran, doktor tarafından fonksiyonel konstipasyon tanısı konmuş 19-64 yaş arasındaki tüm hastalar (59'u kadın 26'sı erkek olmak üzere toplam 85 birey) dahil edilerek yürütülmüştür. Çalışmaya diyabet, kolorektal kanser, Melanosis Coli, hipotroidi, şiddetli hemoroid prolapsus (rektal prolapsus) ve anal fissür hastalığı olmayanlar, kolon cerrahisi geçirmemiş olanlar, sigara, laksatif ve/veya yumuşatıcı kullanmayanlar dahil edilmiştir. Fonksiyonel konstipasyon tanısı doktor tarafindan Roma III kriterleri doğrultusunda konmuştur.

Hastalardan çalışmaya gönüllü olarak katıldıklarına dair yazılı onay formu alınmıştır. Bu çalışma için Başkent Üniversitesi Klinik Araştırmalar Etik Kurulu 14/108 sayılı ve 05.11.2014 tarihli "Etik Kurul Onayı" alınmıştır.

\section{Veri Toplama Araçları}

Hastalara araştırmacı tarafından literatür ve benzer çalışmalardan yararlanılarak hazırlanan 19 sorudan oluşan bir anket formu uygulanmıştır. Anket formunda hastaların demografik özellikleri (yaş, eğitim düzeyi, meslek vb.) sorgulanmıştır. Anket formu araştırmacı tarafından hastalar ile yüz yüze görüşme tekniği ile doldurulmuştur.

Hastalardan, ikisi hafta içi biri hafta sonu olmak üzere toplam üç günlük besin tüketim kaydı alınmıştır. Günlük diyetle alınan enerji ve besin ögeleri, Türkiye için geliştirilen "Bilgisayar Destekli Beslenme Programı, Beslenme Bilgi Sistemleri Paket Programı (BEBİS)" kullanılarak analiz edilmiştir. Hastaların günlük diyet ile enerji ve besin ögeleri alımları, yaşa ve cinsiyete göre önerilen "Diyetle Referans Alım Düzeyi” (Dietary Reference Intake-DRI)’ne göre değerlendirilmiştir (11). Hastaların su dışı sıvı alım miktarlarının değerlendirilmesinde besin tüketim kayıtlarında belirttikleri sıvılar (çay, kahve, maden suyu, gazlı içecekler) göz önünde bulundurulmuştur.

\section{Antropometrik Ölçümler}

Araştırmada yer alan hastaların boy uzunlukları, vücut ağırlıkları, bel ve kalça çevresi ölçümleri yöntemine uygun olarak yapılmış ve kaydedilmiştir. Bireylerin vücut ağırlıkları Tanita BC418 marka biyoelektrik impedans analiz cihazı ile ölçülmüştür. Cihaz ile en doğru ölçümü elde edebilmek amacı ile önerilen ölçüm kurallarına dikkat edilmiştir. Hastaların boy uzunlukları ise Seca marka boy ölçüm aparatı kullanılarak ölçülmüştür. Boy uzunluğu ölçümü yapılırken hastanın ayaklarının yan yana ve başının Frankfurt düzleminde (göz ve kulak kepçesi üstü aynı hizada, baş ile boyun arası 90 derece) olmasına dikkat edilmiştir. Vücut ağırlığının, boy uzunluğunun metre karesine bölünmesi [vücut ağırlığı (kg)/ boy $\left.\left(\mathrm{m}^{2}\right)\right]$ ile hastaların Beden Kütle İndeksleri (BKİ) hesaplanmıştır. Sonuçlar Dünya Sağlık Örgütü (WHO) sınıflamasına göre yorumlanmıştır (12).

Bel çevresi ölçümü, en alt kaburga kemiği ile kristailiak arası bulunup, orta noktadan geçen çevrenin mezura ile ölçülmesi şeklinde yapılmıştır. Kalça çevresi ölçümünde ise hastanın kolları yanda, ayakları yan yana ve dik durmuştur. Hastanın bakışının karşıya doğru ve yere paralel olması (Frankfort düzlemi) sağlanmıştır. Hastanın sağ yanında durularak ölçüm yapılmıştır. Kalçada yandan en yüksek nokta belirlenmiş ve mezura ile çevre ölçümü yapılmıştır. Mezuranın yere paralel olması sağlanmıştır. Hastanın ölçümü mümkün olduğu kadar ince giysiileyapılmıştır. Bu çalışmada bel/kalça oranı değerlendirilirken WHO değerleri referans alınmıştır. Bu yöntemle bel/kalça oranının erkeklerde 0.90, kadınlarda 0.85'in üzerine çıkması android şişmanlık olarak tanımlanmıştır (13).

\section{Verilerin İstatistiksel Değerlendirmesi}

Çalışmada elde edilen veriler, SPSS 15.0 paket programı ile değerlendirilmiştir. Nitel ve nicel değişkenler için 
uygun betimsel değerler verilmiştir. Nitel değişkenler, sayı (n) ve yüzde (\%) olarak, nicel değişkenler ise ortalama ve standart sapma $\left(\overline{\mathrm{X}}_{ \pm} \mathrm{S}\right)$ olarak ifade edilmiştir. Değişkenlerin normal dağılıma uygunluğu Kolmogorov-Smirnov testi ile değerlendirilmiştir. Grupların varyanslarının homojenliği ise Levene testi ile incelenmiştir. Normal dağılım gösteren veriler için Bağımlı Değişkenler Arasındaki Farkın Önemlilik Testi (dependent-t test), normal dağılım göstermeyen veriler için de Mann-Whitney U testi kullanılmıştır. Ölçümle elde edilen normal dağılım göstermeyen değişkenlerin bağımsız iki grupta karşılaştırılması amacıyla Mann-Whitney U testi, ikiden fazla bağımsız grup arasındaki farkın incelenmesinde ise Kruskal Wallis testi uygulanmıştır. Farklılığın anlamlı bulunması durumunda çoklu karşılaştırma testleri ile farklılığı yaratan gruplar saptanmıştır. Kategorik değişkenler bakımından ilişki ya da gruplar arası farklılıkların incelemesinde ki-kare ve/veya Fisher'in exact testi uygulanmıştır. Nitel değişkenler arasındaki ilişkinin belirlenmesi için Ki-kare testi, nicel değişkenler arasındaki ilişkinin belirlenmesinde de İki Yönlü Korelasyon Testi (Pearson) uygulanmıştır. Çalışmaya dair sonuçlar, nitel değişkenlerde oran ve frekans dağılımları, nicel değişkenlerde ise ortanca (en az-en fazla) ile sunulmuştur ve istatistiksel anlamlılık sınırı olarak $\mathrm{p}<0.05$ kabul edilmiştir.

\section{BULGULAR}

Çalışmaya, yaş ortalaması $41.6 \pm 12.64$ yll olan, 59'u kadın (\%69.4), 26’sı erkek (\%30.6) olmak üzere toplam 85 fonksiyonel konstipasyonlu birey katılmıştır. Hastaların büyük çoğunluğu (\%56.4) 42 yaşın altında, üniversite mezunu (\%60) ve çalışmamaktadır (\%48.2). Hastaların BKİ ortalaması 25.5 $\pm 4.42 \mathrm{~kg} /$ $\mathrm{m}^{2}$ olup, erkeklerin BKİ ortalaması $25.8 \pm 3.18 \mathrm{~kg} / \mathrm{m}^{2}$, kadınların BKİ değerleri ortalaması $25.4 \pm 4.89 \mathrm{~kg} / \mathrm{m}^{2}$ olarak bulunmuştur ( $p>0.05)$. Hastaların bel-kalça oranlarının ortalaması incelendiğinde, erkeklerin ortalamasinın $0.90 \pm 0.08$, kadınların ortalamasının $0.82 \pm 0.08$ olduğu görülmüştür (Tablo 1).
Tablo 1. Hastaların çeşitli özelliklerine göre dağılımları $(\mathrm{n}=85)$

\begin{tabular}{|c|c|c|}
\hline Değişkenler & $\mathbf{n}$ & $\%$ \\
\hline \multicolumn{3}{|l|}{ Yaş grupları (yıl) } \\
\hline $21-31$ & 20 & 23.5 \\
\hline $32-42$ & 28 & 32.9 \\
\hline $43-53$ & 15 & 17.7 \\
\hline $54+$ & 22 & 25.9 \\
\hline \multicolumn{3}{|l|}{ Cinsiyet } \\
\hline Kadın & 59 & 69.4 \\
\hline Erkek & 26 & 30.6 \\
\hline \multicolumn{3}{|l|}{ Eğitim düzeyi } \\
\hline Okuryazar değil & 2 & 2.4 \\
\hline İlkokul mezunu & 8 & 9.4 \\
\hline Ortaokul mezunu & 5 & 5.9 \\
\hline Lise mezunu & 19 & 22.3 \\
\hline Yüksekokul/üniversite mezunu & 51 & 60.0 \\
\hline \multicolumn{3}{|l|}{ Mesleği } \\
\hline Çalışmıyor/ev hanımı & 24 & 28.2 \\
\hline Öğrenci & 6 & 7.1 \\
\hline Emekli & 11 & 12.9 \\
\hline İşçi & 26 & 30.6 \\
\hline Memur & 5 & 5.9 \\
\hline Serbest meslek & 13 & 15.3 \\
\hline BKİ $\left(\mathbf{k g} / \mathbf{m}^{2}\right)$ & $\overline{\mathbf{X}}_{ \pm} \mathbf{S}$ & En az-En fazla \\
\hline Kadın & $25.4 \pm 4.89$ & $16.7-36.9$ \\
\hline Erkek & $25.8 \pm 3.18$ & $22.1-36.0$ \\
\hline Bel/kalça oranı & $\overline{\mathbf{X}} \pm \mathbf{S}$ & En az-En fazla \\
\hline Kadın & $0.82 \pm 0.08$ & $0.67-1.00$ \\
\hline Erkek & $0.90 \pm 0.08$ & $0.80-1.04$ \\
\hline
\end{tabular}

Hastaların günlük ortalama su alım miktarları (mL) incelendiğinde kadın hastaların günlük su alım miktarının erkek hastaların günlük su alım miktarından istatistiksel olarak anlamlı şekilde fazla olduğu bulunmuştur $(\mathrm{p}<0.05)$. Hastaların günlük su dışındaki sıvı alım miktarları (mL) incelendiğinde ortalama 405.1 $\pm 249.3 \mathrm{~mL}$ sıvı aldıkları görülmektedir. Erkeklerin günlük su dışı sıvı alımları kadınların günlük su dışı sıvı alımlarından istatistiksel olarak anlamlı şekilde fazladır ( $\mathrm{p}<0.05)$ (Tablo 2). 
Hastaların günlük diyetle aldıkları posa miktarlarının

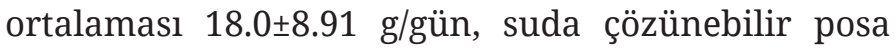
miktarlarının ortalaması $5.9 \pm 4.60$ g/gün, suda çözünmeyen posa miktarlarının ortalaması 11.5 \pm 4.59 g/gün olarak bulunmuştur. Hastaların günlük diyetle aldıkları posa miktarlarının ortalamaları kadınlarda

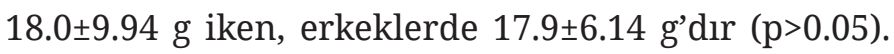
Kadınların ortalama $5.8 \pm 5.37 \mathrm{~g}$, erkeklerin ortalama $6.0 \pm 2.05$ g suda çözünebilir posa, kadınların ortalama
$11.6 \pm 4.83 \mathrm{~g}$, erkeklerin ise ortalama $11.4 \pm 4.08 \mathrm{~g}$ suda çözünmeyen posa aldıkları belirlenmiştir ( $p>0.05$ ). Hastaların toplamda \%71.8'i günlük $20 \mathrm{~g}$ posadan daha az miktarda posa tüketerek posa gereksinmesini karşılayamamıştır. Kadınların \%72.9’u, erkeklerin \%69.2'si yetersiz düzeyde posa alırken aradaki fark istatistiksel olarak anlamlı bulunmamıştır ( $p>0.05)$ (Tablo 2).

Tablo 2. Hastaların günlük diyetle sıvı ve posa alımları ile posa alım yeterliliğinin değerlendirilmesi ( $\mathrm{n}=85)$

\begin{tabular}{|c|c|c|c|c|c|c|c|}
\hline \multirow{2}{*}{$\begin{array}{l}\text { Sivı ve posa alım } \\
\text { miktarları }\end{array}$} & \multicolumn{2}{|c|}{ Kadın } & \multicolumn{2}{|c|}{ Erkek } & \multicolumn{2}{|c|}{ Toplam } & \multirow{2}{*}{$\mathbf{P}$} \\
\hline & $\overline{\mathbf{X}} \pm \mathbf{S}$ & En az-En fazla & $\overline{\mathbf{X}} \pm \mathbf{S}$ & En az-En fazla & $\overline{\mathbf{X}} \pm \mathbf{S}$ & En az-En fazla & \\
\hline Su alım miktarı (mL) & $1413.6 \pm 842.5$ & $400.0-4200.0$ & $1084.6 \pm 617.5$ & $400.0-3000.0$ & $1312.9 \pm 791.74$ & $=400.0-4200.0$ & $0.035^{*}$ \\
\hline $\begin{array}{l}\text { Su dışı sıvı alım miktarı } \\
(\mathrm{mL})\end{array}$ & $366.7 \pm 256.6$ & $55.9-1024.5$ & $489.2 \pm 213.6$ & $173.0-1177.3$ & $405.1 \pm 249.3$ & $55.9-1177.3$ & $0.037^{*}$ \\
\hline Posa (g) & $18.0 \pm 9.94$ & $6.6-79.6$ & $17.9 \pm 6.14$ & $9.8-34.2$ & $18.0 \pm 8.91$ & $6.6-79.6$ & 0.782 \\
\hline Suda çözünebilir posa (g) & $5.8 \pm 5.37$ & $2.0-43.4$ & $6.0 \pm 2.05$ & $3.1-10.3$ & $5.9 \pm 4.60$ & $2.0-43.4$ & 0.112 \\
\hline Suda çözünmeyen posa (g) & $11.6 \pm 4.83$ & $4.3-36.0$ & $11.4 \pm 4.08$ & $6.2-23.6$ & $11.5 \pm 4.59$ & $4.3-36.0$ & 0.767 \\
\hline \multicolumn{8}{|c|}{ Diyetle günlük alınan posa } \\
\hline \multirow{2}{*}{ Cinsiyet } & \multicolumn{2}{|c|}{ Yetersiz (<20 g) } & \multicolumn{2}{|c|}{ Normal (20-35 g) } & \multicolumn{2}{|c|}{ Fazla (>35 g) } & \multirow{2}{*}{$\mathbf{P}$} \\
\hline & $\mathbf{n}$ & $\%$ & $\mathbf{n}$ & $\%$ & $\mathbf{n}$ & $\%$ & \\
\hline Kadın & 43 & 72.9 & 14 & 23.7 & 2 & 3.4 & \\
\hline Erkek & 18 & 69.2 & 8 & 30.8 & 0 & 0 & 0.532 \\
\hline Toplam & 61 & 71.8 & 22 & 25.9 & 2 & 2.3 & \\
\hline
\end{tabular}

${ }^{*} p<0.05$

Bireylerin günlük vitamin ve mineral ortalamaları incelendiğinde A vitamini $904.5 \pm 675.17 \mathrm{mcg} \mathrm{RE}, \mathrm{E}$ vitamini $12.8 \pm 5.44 \mathrm{mg}$, tiamin $0.7 \pm 0.23 \mathrm{mg}$, riboflavin $1.1 \pm 0.27 \mathrm{mg}$, niasin $9.5 \pm 3.52 \mathrm{mg}, \mathrm{B}_{6}$ vitamini $0.9 \pm 0.31$ $\mathrm{mg}$, C vitamini $77.2 \pm 51.03 \mathrm{mg}$, folat $104.5 \pm 33.94 \mathrm{mcg}$, $\mathrm{B}_{12}$ vitamini $3.2 \pm 1.82 \mathrm{mcg}$, sodyum $3387.2 \pm 987.70 \mathrm{mg}$, potasyum $1808.4 \pm 543.72 \mathrm{mg}$, magnezyum $232.3 \pm 85.99$ $\mathrm{mg}$, kalsiyum $669.5 \pm 212.96 \mathrm{mg}$, fosfor $939.4 \pm 271.57$ $\mathrm{mg}$, demir $9.1 \pm 3.32 \mathrm{mg}$, çinko $9.2 \pm 2.49 \mathrm{mg}$ ve bakır $1.8 \pm 0.56 \mathrm{mg}$ olarak bulunmuştur (Tablo 3 ).

Hastaların vitamin gereksinimlerini karşılama durumları incelendiğinde kadınların \%22'sinin, erkeklerin \%30.8'inin ve tüm bireylerin \%24.7’sinin A vitamininden, kadınların \%39.0'unun, erkeklerin \%23.1'inin, tüm bireylerin \%34.1'inin E vitamininden, kadınların \%83.1'inin, erkeklerin \%69.2'sinin, tüm bireylerin \%78.8'inin tiaminden, kadınların \%18.6'sının, erkeklerin \%7.7’sinin, tüm bireylerin \%15.3’ünün riboflavinden, kadınların \%72.9'unun, erkeklerin \%46.2'sinin, tüm bireylerin \%64.7'sinin niasinden, kadınların \%47.5'inin, erkeklerin \%84.6'sinin ve tüm bireylerin \%58.8'inin $\mathrm{B}_{6}$ vitamininden $\quad(\mathrm{p}<0.05)$, kadınların \%45.8'inin, erkeklerin \%46.2'sinin, tüm bireylerin \%45.9'unun C vitamininden, kadın ve erkek hastaların tümünün folattan, kadınların \%15.3'ünün, erkeklerin \%3.8'inin, tüm bireylerin \%11.8'inin $\mathrm{B}_{12}$ vitamininden yetersiz beslendiği bulunmuştur (Tablo 4).

Hastaların mineral gereksinimlerini karşılama durumları incelendiğinde, kadınların \%44.1'inin, erkeklerin \%76.9'unun, tüm bireylerin \%54.1'inin sodyum alımları gereksinimlerinden fazladır 
(p<0.05). Kadınların \%84.7'si, erkeklerin \%84.6'sı, tüm bireylerin \%84.7'si potasyum, kadınların \%50.8'i, erkeklerin \%69.2'si, tüm bireylerin \%56.5’i kalsiyum, kadınların \%81.4'ü, erkeklerin \%80.8’i, tüm bireylerin \%81.2'si magnezyum, kadınların \%78'i demir açısından yetersiz bulunmuştur. Hastaların \%80.0’i çinkoyu yeterli düzeyde tüketmektedir. Erkek hastaların yetersiz çinko alım düzeyi (\%11.5) kadın hastaların yetersiz çinko alım düzeyinden (\%3.4) daha yüksektir ( $\mathrm{p}>0.05)$. Hastaların \%8.2'sinin bakır alımı normal iken \%91.8'inin bakır alımı fazla bulunmuştur. Bakırı fazla alan kadınların sıklığı (\%88.1) erkeklerin sıklığından (\%100.0) daha düşüktür (p>0.05) (Tablo 4).

Tablo 3. Hastaların diyetle aldıkları günlük vitamin ve mineral ortalamaları $\left(\overline{\mathrm{X}}_{ \pm} \mathrm{S}\right)$ ve alt-üst değerleri $(\mathrm{n}=85)$

\begin{tabular}{|c|c|c|c|c|c|c|c|}
\hline \multirow{2}{*}{$\begin{array}{l}\text { Vitaminler ve } \\
\text { mineraller }\end{array}$} & \multicolumn{2}{|c|}{ Kadın $(n=59)$} & \multicolumn{2}{|c|}{ Erkek $(n=26)$} & \multicolumn{2}{|c|}{ Toplam $(n=85)$} & \multirow[b]{2}{*}{$\mathbf{p}$} \\
\hline & $\overline{\mathbf{X}} \pm \mathbf{S}$ & En az-En fazla & $\overline{\mathbf{X}} \pm \mathbf{S}$ & En az-En fazla & $\overline{\mathbf{X}} \pm \mathbf{S}$ & $\overline{\text { En az-En fazla }}$ & \\
\hline A vitamini (mcg RE) & $864.1 \pm 633.26$ & $263.9-4657.7$ & $996.4 \pm 767.28$ & $292.3-3735.4$ & $904.5 \pm 675.17$ & $263.9-4657.7$ & 0.647 \\
\hline E vitamini (mg) & $12.3 \pm 5.57$ & $3.3-27.4$ & $13.8 \pm 5.08$ & $3.3-24.2$ & $12.8 \pm 5.44$ & $3.3-11.9$ & 0.235 \\
\hline Tiamin (mg) & $0.6 \pm \pm 0.23$ & $0.3-1.6$ & $0.7 \pm 0.23$ & $0.4-1.5$ & $0.7 \pm 0.23$ & $0.3-1$ & 0.147 \\
\hline Riboflavin (mg) & $1.1 \pm 0.31$ & $0.5-1.9$ & $1.1 \pm 0.27$ & $0.7-1.9$ & $1.1 \pm 0.27$ & $0.54-1.9$ & 0.388 \\
\hline Niasin (mg) & $9.0 \pm 3.30$ & $3.4-20.9$ & $10.6 \pm 3.79$ & $5.5-21.8$ & $9.5 \pm 3.52$ & $3.4-21.8$ & $0.034^{*}$ \\
\hline $\mathrm{B}_{6}$ vitamini (mg) & $0.9 \pm 0.34$ & $0.5-2.1$ & $1.0 \pm 0.25$ & $0.5-1.6$ & $0.9 \pm 0.31$ & $0.5-2.1$ & 0.151 \\
\hline C vitamini (mg) & $78.0 \pm 47.52$ & $3.7-233.6$ & $75.2 \pm 59.21$ & $12.0-325.3$ & $77.2 \pm 51.03$ & $3.7-325.3$ & 0.554 \\
\hline Folat (mcg) & $104.2 \pm 36.31$ & $46.5-248.6$ & $105.0 \pm 28.51$ & $58.6-165.2$ & $104.5 \pm 33.94$ & $46.5-248.6$ & 0.689 \\
\hline $\mathrm{B}_{12}$ vitamini (mcg) & $2.9 \pm 1.39$ & $0.9-7.7$ & $3.8 \pm 2.47$ & $1.45-14.4$ & $3.2 \pm 1.82$ & $0.9-14.4$ & 0.076 \\
\hline Sodyum (mg) & $3168.8 \pm 925.09$ & 1384.4-5097.9 & $3882.9 \pm 961.39$ & 2020.0-5998.9 & $3387.2 \pm 987.70$ & 1384.4-5998.9 & $0.002^{*}$ \\
\hline Potasyum (mg) & $1815.3 \pm 566.72$ & 1006.0-3350.5 & $1773.2 \pm 496.91$ & $976.5-3330.1$ & $1808.4 \pm 543.72$ & $976.5-3350.5$ & 0.947 \\
\hline Kalsiyum (mg) & $679.2 \pm 234.40$ & $266.7-1562.1$ & $647.7 \pm 155.60$ & $397.3-1118.8$ & $669.5 \pm 212.96$ & $266.7-1562.1$ & 0.767 \\
\hline Magnezyum (mg) & $236.1 \pm 92.87$ & 132.3-599.5 & $223.8 \pm 68.74$ & $144.4-474.0$ & $232.3 \pm 85.99$ & $132.3-599.5$ & 0.879 \\
\hline Fosfor (mg) & $923.4 \pm 285.54$ & $427.5-2034.0$ & $975.6 \pm 238.06$ & 567.3-1753.4 & $939.4 \pm 271.57$ & $427.5-2034.0$ & 0.164 \\
\hline Demir (mg) & $8.9 \pm 3.56$ & $4.8-27.2$ & $9.5 \pm 2.73$ & $5.7-16.5$ & $9.1 \pm 3.32$ & $4.8-27.2$ & 0.150 \\
\hline Çinko (mg) & $8.9 \pm 2.54$ & $4.4-17.6$ & $9.9 \pm 2.25$ & 6.3-15.4 & $9.2 \pm 2.49$ & $4.4-17.6$ & $0.029 *$ \\
\hline Bakır (mcg) & $1.8 \pm 0.61$ & $0.9-3.9$ & $1.8 \pm 0.43$ & $1.2-3.0$ & $1.8 \pm 0.56$ & $0.9-3.9$ & 0.703 \\
\hline
\end{tabular}

${ }^{*} p<0.05$, RE: retinol eşdeğeri, mg: miligram, mcg: mikrogram

\section{TARTIŞMA}

Konstipasyon, genel popülasyonda sindirim sistemiyle ilgili en sık görülen şikayettir ve ekonomik kayba yol açar (14). Konstipasyonda genellikle hastalar bağırsak işlevlerinde anormallik hisseder, dışkılama sayısı azalır, alt karın bölgesinde rahatsızlık, gerginlik ve şişkinlik tanımlarlar (15). Her şeyden önce konstipasyon, kişiden kişiye değişen ve farklı şekillerde yorumlanan subjektif bir semptomdur, bir hastalık değildir (16).

Prevalans çalışmalarına göre kadınlarda erkeklere göre fonksiyonel konstipasyon görülme oranı 2-3 kat fazladır (17). Bu çalışmada da fonksiyonel konstipasyonu olan kadın hastalar (\%69.4), erkek hastalardan (\%30.6) daha fazladır. Kuzey Amerika'da kadınlarda erkeklere kıyasla $2.2 \mathrm{kez}$ daha fazla konstipasyon sıklı̆̆ı görülmüştür (18). Kadınlardaki bu çoğunluk hormonal etmenlere bağlanmaktadır. Menstrüel döngünün luteal fazı sırasında, progesteronun etkisi altında ve doğum ya da jinekolojik ameliyatlar sırasında oluşabilecek pelvik taban kası hasarında konstipasyon riski artış göstermektedir (19).

Araştırmaya katılan hastaların eğitim düzeyi incelendiğinde hastaların çoğunluğunun (\%60.0) 


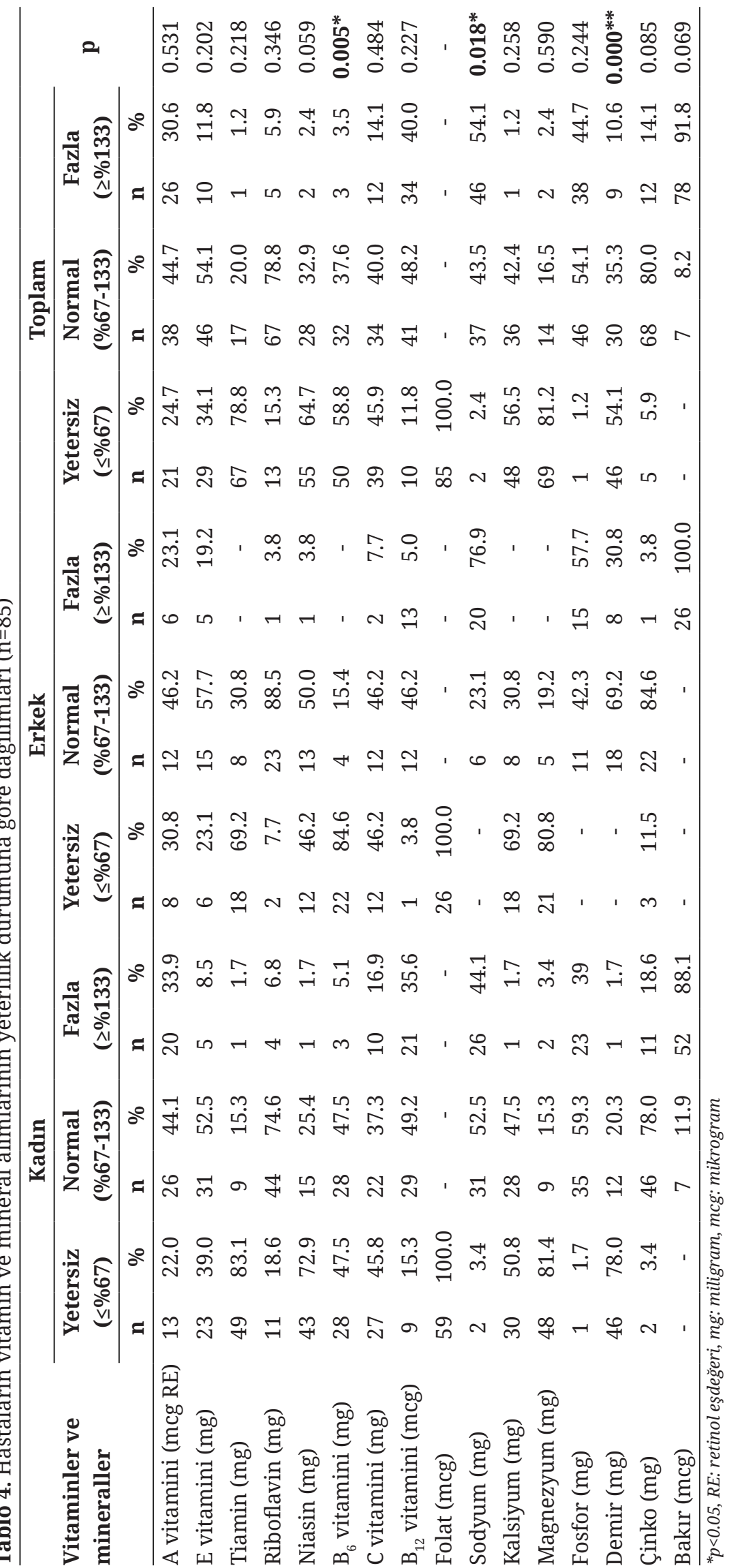


yüksek okul/üniversite mezunu olduğu, \%22.4’ünün lise mezunu olduğu, \%17.7'sinin orta okul mezunu ve altı olduğu görülmektedir. Ancak yapılan çalışmalara göre konstipasyon, eğitim düzeyinden etkilenmektedir. Eğitim düzeyi daha düşük olanlarda daha yüksek olanlara göre konstipasyon daha sık görülmektedir (20,21). Bu durum hastaların eğitim düzeyi artsa da konstipasyon, sağlıklı beslenme ve posa konuları ile ilgili gerekli ve yeterli bilgiye sahip olmamalarından kaynaklanabilir.

Konstipasyon sıklığı yaş ilerledikçe artarak yaşam kalitesini olumsuz yönde etkilemektedir (22,23). Yaş ilerledikçe daha sık görülmesindeki etiyolojik etmenler farklılık göstermekle birlikte temel nedenler komorbiditelerin varlığı ve sedanter yaşam tarzıdır (23). Bu çalışmada bireylerin yaş ortalaması

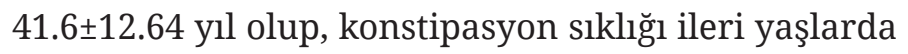
daha fazla görülmüştür ve hastaların \%25.9'unun 54 yaş ve üzerinde olduğu bulunmuştur.

Obezite tüm dünyada hızla artan büyük bir sağlık sorunudur. Birçok hastalığı beraberinde getiren obezite fonksiyonel gastrointestinal hastalıklar için de risk etmenidir. Ayrıca obezitenin etiyolojisinde rol oynayan sağlıksız beslenme, sigara kullanımı, aşırı alkol alımı ve yetersiz fiziksel aktivite gibi etmenlerin konstipasyon üzerinde de etkili olduğu görülmektedir (24). Yetişkin bireylerde ( $\mathrm{n}=$ 18.780) yapılan bir çalışmada hastaların 459'unda fonksiyonel konstipasyon saptanmıştır. Hastaların ortalama BKİleri $26.5 \pm 4.7 \mathrm{~kg} / \mathrm{m}^{2}$ bulunmuştur ve hastaların \%60'ının BKI'si 25'in üzerindedir (25). Bu çalışmada da hastaların ortalama BKİ'si $25.5 \pm 4.42 \mathrm{~kg} /$ $\mathrm{m}^{2}$ bulunmuştur ve hastaların \%45.9'unun BKİsi 25 $\mathrm{kg} / \mathrm{m}^{2}$ 'den yüksektir. Çalışmada posa alım düzeyleri yetersiz ve fazla olan bireylerin BKİlerinin 25'in üstünde olduğu görülmüştür. Bu durum hafif şişman ve obez bireylerin karbonhidrat ve yağ içeriği yüksek, posa içeriği düşük olan besinleri daha çok tercih etmelerinden kaynaklanıyor olabilir.

Obez bireylerin bağırsak floraları sağlıklı bireylere kıyasla mikrobiyal sayı ve çeşitlilik olarak farklılık göstermektedir. Bu farklılık ise çeşitli biyomekanizmaları etkileyerek obezitenin gelişmesi ve ilerlemesini tetiklemektedir. Obez bireylerin posa gereksinimlerini günlük önerilen düzeylere çıkarmaları, biyoyararlılığı yüksek bakterilerin arttırılması ve üretilen kısa zincirli yağ asitlerinin artışı, bağırsak permeabilitesinin yükselmesi vb. birçok etki sonucu obezite ve inflamatuvar ve gastrointestinal hastalıkların komplikasyonlarının azaltılmasında etkili olmaktadır $(26,27)$.

Yetersiz sıvı alımının genel olarak konstipasyonun risk etmeni olarak kabul edilmesine rağmen, sıvı alımının arttırılması ile konstipasyonun iyileştiğine yönelik kanıta dayalı çalışma yoktur (28). Bir konstipasyon hastasının sıvı alımının her gün en az 1500-2000 mL olması gerekmektedir ve bu hastanın diyet tedavisi ile posa alımı 20-35 grama çıktığı zaman sıvı alımı da günlük 2 litreye çıkarılmalıdır (5). Bu çalışmada hastaların günlük su alım miktarları ortalama $1312.9 \pm 791.74 \mathrm{~mL}$ bulunmuştur. Bu miktar önerilen günlük 2 litreden azdır (5). Kadınların günlük ortalama su alım miktarı (1413.6 $\pm 842.5 \mathrm{~mL}$ ) erkeklerin alım miktarından (1084.6 $\pm 617.5 \mathrm{~mL})$ istatistiksel olarak anlamlı şekilde fazladır. Kadınların su ve posa alım miktarlarının erkeklerden daha fazla olmasına karşılık konstipasyon sıklığının kadınlarda daha fazla görülmesi, cinsiyetler arası hormonal ve kolonik düz kas hücrelerindeki progesteron reseptörlerinin farklılığından kaynaklanıyor olabilir.

Kanada Diyetisyenler Derneği, kan kolesterol düzeyini düşürücü etkisinin sağlanması için günlük en az $10 \mathrm{~g}$ çözünebilir posanın hedeflenmesini önermektedir (29). Çalışmada hastaların ortalama suda çözünebilen posa alım miktarı $5.9 \pm 4.60 \mathrm{~g}$ olarak bulunmuştur. Çözünür posanın kolesterol düşürücü etkisinin yanı sıra mide içeriğinin viskozitesini arttırarak midenin boşalmasını geciktirmesi ve besin alımı azaltması da düşünülecek olursa özellikle obezite ve etkilerinin iyileştirilmesinde olumlu sonuçlar doğuracağından bu hastalar için çözünür posa alımının arttırılması önerilmelidir (30).

Diyet posasının özellikle de çözünmez posanın fazla tüketilmesi, vücuttaki minerallerin bağlanmasına 
veya bağırsak geçiş süresinin kısalması ile mineral yararlılığının azalmasına neden olabilir. Diyet posası özellikle kalsiyum, magnezyum, demir ve çinko gibi mineralleri yüksek oranda bağlayabilir (31). Diyet posasının yüksek miktarlarda alınması bazı vitaminlerin biyoyararlılığını azaltmakta ve/veya atımını arttırmaktadır (32). Çalışmada hastaların tiamin, niasin, $B_{6}$ ve $E$ vitaminleri ile potasyum, kalsiyum, magnezyum ve demir minerallerinin alımında yüksek miktarda yetersizlikler olduğu görülmüştür. Yaşlanmanın vitamin ve minerallerin biyoyararlılığı üzerinde olumsuz etkisi vardır ve hastalardaki mevcut eksiklik, yaşlılık dönemindeki yetersizliğin şiddetini arttırarak yaşlılıktaki katabolik etkiyi arttırabilir. Hastaların posa alımlarının arttırılması ile vitamin ve mineralden zengin besin alımı da arttırılmış olacağından, yaşlılıktaki bu olumsuz etki önlenebilir $(33,34)$.

Sonuç olarak yapılan bu çalışma daha önceki çalışmaları destekler nitelikte olup çalışma sonucunda fonksiyonel konstipasyonu olan bireylerin su ve posa alımlarının yetersiz olduğu, günlük diyet ile yetersiz vitamin ile mineral aldıkları görülmüştür. Bireylerin konstipasyon bulgularının düzelmesi, yeterli ve dengeli beslenmesi ve daha sağlıklı bir yaşam sürmeleri amacıyla sağlıklı beslenme, diyet posası, vitamin ve mineral alımları konusunda bilgi düzeylerinin arttırılmasına yönelik çalışmaların yaygınlaştırılması önemlidir. Bu çalışmaların aktif bir şekilde diyetisyenler tarafından gerçekleştirilmesi, fiziksel aktivite düzeylerinin arttırılması için halkın bilinçlendirilmesi ve egzersize teşvik edilmesi ile ilgili çalışmalar yapılması önerilmektedir.

Çıkar çatışması - Conflict of interest: Yazarlar çıkar çatışması olmadığını beyan ederler. - The authors declare that they have no conflict of interest.

\section{KAYNAKLAR}

1. Lembo A, Camilleri M. Chronic constipation. N Engl J Med 2003;349 (14):1360-8.

2. Talley NJ. Definitions, epidemiology and impact of chronic constipation. Rev Gastroenterol Disord 2004;4(Suppl 2):3-10.
3. Roque MV, Bouras EP. Epidemiology and management of chronic constipation in elderly patients. Clin Interv Aging 2015;10:919-30.

4. Forootan M, Bagheri N, Darvishi M. Chronic constipation. Medicine (Baltimore) 2018;97(20):e10631.

5. Folden SL. Practice guidelines for the management of constipation in adults. Rehabil Nurs 2002;27(5):169-75.

6. Dülger D, Şahan Y. Diyet lifin özellikleri ve sağllk üzerindeki etkileri. U.Ü. Ziraat Fakültesi Dergisi 2011; 25(2):147-57.

7. Samur G, Mercangil S. Diyet posası ve beslenme. T.C. Sağlık Bakanlığı Temel Sağlık Hizmetleri Genel Müdürlüğü Beslenme ve Fiziksel Aktiviteler Daire Başkanlığı, Klasmat Matbaacılık, Ankara, 2008;s.3-28.

8. Axelrod CH, Saps M. The role of fiber in the treatment of functional gastrointestinal disorders in children. Nutrients 2018;10(11):1650-666.

9. Papandreou DP, Noor ZT, Rashed M. The role of soluble, insoluble fibers and their bioactive compounds in cancer: a mini review. Food Nutr Sci 2015;6:1-11.

10. U.S. Department of Agriculture (USDA), U.S. Department of Health and Human Services (HHS). Dietary Guidelines for Americans 2010. 7th Edition, Washington, DC: U.S. Government Printing Office, December 2010.p.1-91.

11. National Institutes of Health (NIH). Nutrient recommendations: dietary reference intakes (DRI). Available at: https://ods.od.nih.gov/Health_Information/ Dietary_Reference_Intakes.aspx. Accessed December $03^{\text {rd }}, 2018$

12. World Health Organization (WHO), Global database on body mass index. Available at: http://apps.who.int/bmi/ index.jsp?introPage=intro_3.html. Accessed December $09^{\text {th }}, 2018$.

13. World Health Organization (WHO), Waist Circumference and Waist-Hip Ratio. Report of a WHO Expert Consultation Geneva 2008. Available at: http://apps.who. int/iris/bitstream/handle/10665/44583/9789241501491 eng.pdf? sequence=1. Accessed December 09 ${ }^{\text {th }}, 2018$.

14. Singh G, Lingala V, Wang H, Vadhavkar S, Kahler KH, Mithal A, et al. Use of health care resources and cost of care for adults with constipation. Clin Gastroenterol Hepatol 2007;5(9):1053-8.

15. Lindberg G, Hamid S, Malfertheiner P., Thomsen O, Fernandez LB, Garisch J, et al. Constipation: a global perspective. World Gastroenterology Organisation Global Guidelines 2010. Available at: http://www. worldgastroenterology.org/UserFiles/file/guidelines/ constipation-english-2010.pdf. Accessed September 19 2018.

16. Bengi G, Yalçın M, Akpınar H. Kronik konstipasyona güncelyaklaşım. Güncel Gastroenteroloji 2014;18(2):18197. 
17. McCrea GL, Miaskowski C, Stotts NA, Macera L, Varma MG. A review of the literature on gender and age differences in the prevalence and characteristics of constipation in North America. J Pain Symptom Manage 2009;37(4):737-45.

18. Higgins PD, Johanson JF. Epidemiology of constipation in North America: a systematic review. Am J Gastroenterol 2004;99(4):750-9.

19. Chiarelli P, Brown W, McElduff P. Constipation in Australian women: prevalence and associated factors. Int Urogynecol J Pelvic Floor Dysfunct 2000;11(2):71-8.

20. Mugie SM, Benninga MA, Di Lorenzo C. Epidemiology of constipation in children and adults: a systematic review. Best Pract Res Clin Gastroenterol 2011;25(1):3-18.

21. Suares NC, Ford AC. Prevalence of, and risk factors for, chronic idiopathic constipation in the community: systematic review and meta-analysis. Am J Gastroenterol 2011;106(9):1582-91.

22. Rasquin A, Di Lorenzo C, Forbes D, Guiraldes E, Hyams JS, Staiano A, et al. Childhood functional gastrointestinal disorders: child/adolescent. Gastroenterology 2006;130(5):1527-37.

23. Chokhavatia S, John ES, Bridgeman MB, Dixit D. Constipation in elderly patients with noncancer pain: focus on opioid-induced constipation. Drugs Aging 2016;33(8):557-74.

24. Costa ML, Oliveira JN, Tahan S, Morais MB. Overweight and constipation in adolescents. BMC Gastroenterol 2011;11:40-5.

25. Pourhoseingholi MA, Kaboli SA, Pourhoseingholi A, Moghimi-Dehkordi B, Safaee A, Mansoori BK, et al.
Obesity and functional constipation; a community-based study in Iran. J Gastrointestin Liver Dis 2009;18(2):151-5.

26. Scwiertz A, Taras D, Schafer K, Beijer S, Bos NA, Donus $\mathrm{C}$, et al. Microbiota and SCFA in lean and overweight healthy subjects. Obesit 2010;18(1):190-5.

27. Indias IM, Cardona F, Tinahones FJ, Queipo-Ortuno MI. Impact of the gut microbiota on the development of obesity and type 2 diabetes mellitus. Front Microbiol 2014;5:190-200.

28. Lindeman RD, Romeo LJ, Lian HC, Baumgartner RN, Koehler KM, Garry PJ. Do elderly persons need to be encouraged to drink more fluids? J Gerontol A Biol Sci Med Sci 2000;55(7):361-5.

29. Dietitians of Canada. Food sources of soluble fibre. The Global Resource for Nutrition Practice, 2012. Available at: https://carleton.ca/healthy-workplace/wp-content/ uploads/soluble-fibre.pdf. Accessed July 26 $6^{\text {th }}, 2018$.

30. Papandreou D, Noor ZT, Rashed M. The role of soluble, insoluble fibers and their bioactive compounds in cancer: a mini review. Food Nutr Sci 2015;6:1-11.

31. Casterline JL, Ku Y. Binding of zinc to apple fiber, wheat bran, and fiber components. J Food Sci 1993;58(2):365-8.

32. Thebaudin JY, Lefebvre AC, Harrington M, Bourgeois CM. Dietary fibres: nutritional and technological interest. Trends Food Sci Tech 1997;8(2):41-8.

33. Huskisson E, Magginis, Ruf M. The role of vitamins and minerals in energy metabolism and well-being. J Int Med Res 2007;35(3):277-89.

34. Donini LM, Savina C, Cannella C. Nutrition in the elderly: role of fiber. Arch Gerontol Geriatr 2009;49(1):61-9. 